\title{
Optical Sensing and Switching with Designed Molecules
}

\author{
A. Prasanna de Silva* and David C. Magri
}

\begin{abstract}
Some of the recent research in optical sensor and switch molecules at Queen's University of Belfast is outlined. The ion-induced absorption spectral changes of molecules with ICT (Internal Charge Transfer) excited states are used to demonstrate superposed logic where multiple logic configurations are simultaneously observable. Similar spectral effects in multi-receptor structures give rise to XOR logic. The ion-induced luminescent spectral changes of molecules with ICT excited states can be combined with the phenomenon of Photoinduced Electron Transfer (PET) to exemplify tristable systems. Insights can also be gained into the luminescence effects initiated in designed molecules by transition metal ions in non-aqueous media. The ion-induced luminescent spectral changes of PET systems with one or two receptors display YES and AND logic respectively. The latter yield coincidence sensors for the direct detection of ion pairs. Overall, interesting optical sensors and switches can be produced from rather small molecules when the latter are fitted with ion-receptors.
\end{abstract}

Keywords: Fluorescent ICT sensors · Fluorescent PET sensors · Indicators · Molecular logic gates

\section{Introduction}

Since molecules or atoms operate in a far smaller domain than ours, we need special molecules on location so that scientists can learn the secrets of the molecular world. Optically empowered molecules do this job very well. Suitable signals are wavelength shifts in electronic absorption spectra, or in fluorescence emission spectra or even better, fluorescence quantum yield changes in the case of the latter. Combining different functional units in different ways is a productive approach of obtaining chemically-induced optical signals [1]. Wavelength shifts are produced from integrated 'Chromo/Fluorophore-Receptor' formats accommodating internal charge transfer (ICT) excited states [2]. 'Fluorophore-Spacer-Receptor' formats involve photoinduced electron trans-
${ }^{\star}$ Correspondence: Prof. Dr. A.P. de Silva,

Dr. D.C. Magri

Queen's University

School of Chemistry

Stranmillis Road

Belfast BT9 5AG

Northern Ireland

Tel: : +442890974422

Fax: +44 2890974687

E-Mail: a.desilva@qub.ac.uk; d.magri@qub.ac.uk

www.ch.qub.ac.uk/staff/desilva/apds.html fer (PET), which can switch 'off' fluorescence emission. This can be chemically reversed so that the fluorescence quantum yield becomes high again [2]. Expansion of the above formats to accommodate two receptors produces 'Receptor ${ }_{1}$-Chromophore-Receptor 2 ' and 'Receptor ${ }_{1}$-Spacer $_{1}$ Fluorophore-Spacer -Receptor $_{2}{ }^{\prime}$ systems. These two basic formats can also be fused to create a 'Fluorophore-Receptor ${ }_{1}$-SpacerReceptor $_{2}$ ' system. Each of these systems has its sensory/switching uses, as we will demonstrate.

\section{2. 'Chromophore-Receptor' Systems}

1 [3] is a 'chromophore-receptor' system containing a dye structure with a conjugated $\pi$-electron set, with individual donor and acceptor terminals. 1 also contains a tetra-anionic chelating site for multivalent cations. So it is not at all surprising that $\mathrm{Ca}^{2+}$ perturbs the ICT excited state of $\mathbf{1}$, with a resulting blue shift in the UV-Vis absorption spectrum (Fig. 1). From a molecular logic viewpoint [4], let's take $\mathrm{Ca}^{2+}$

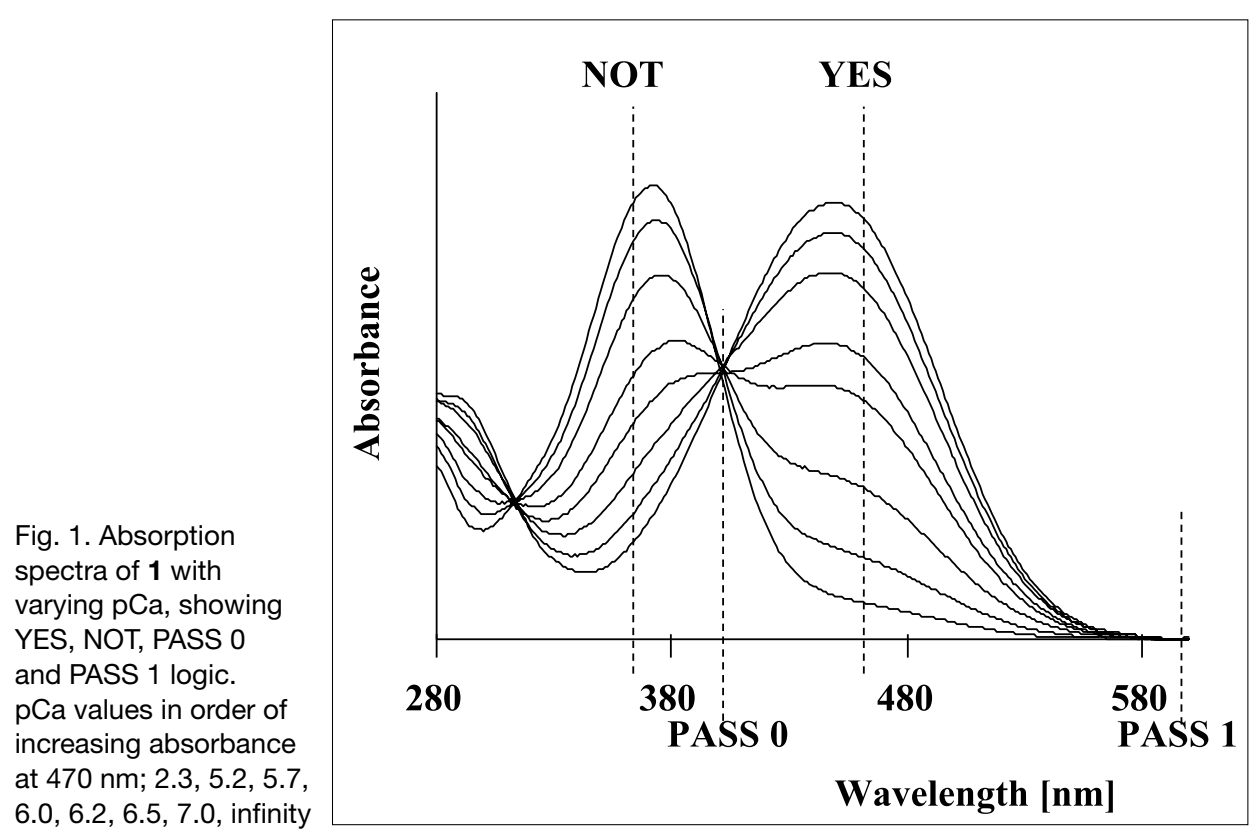




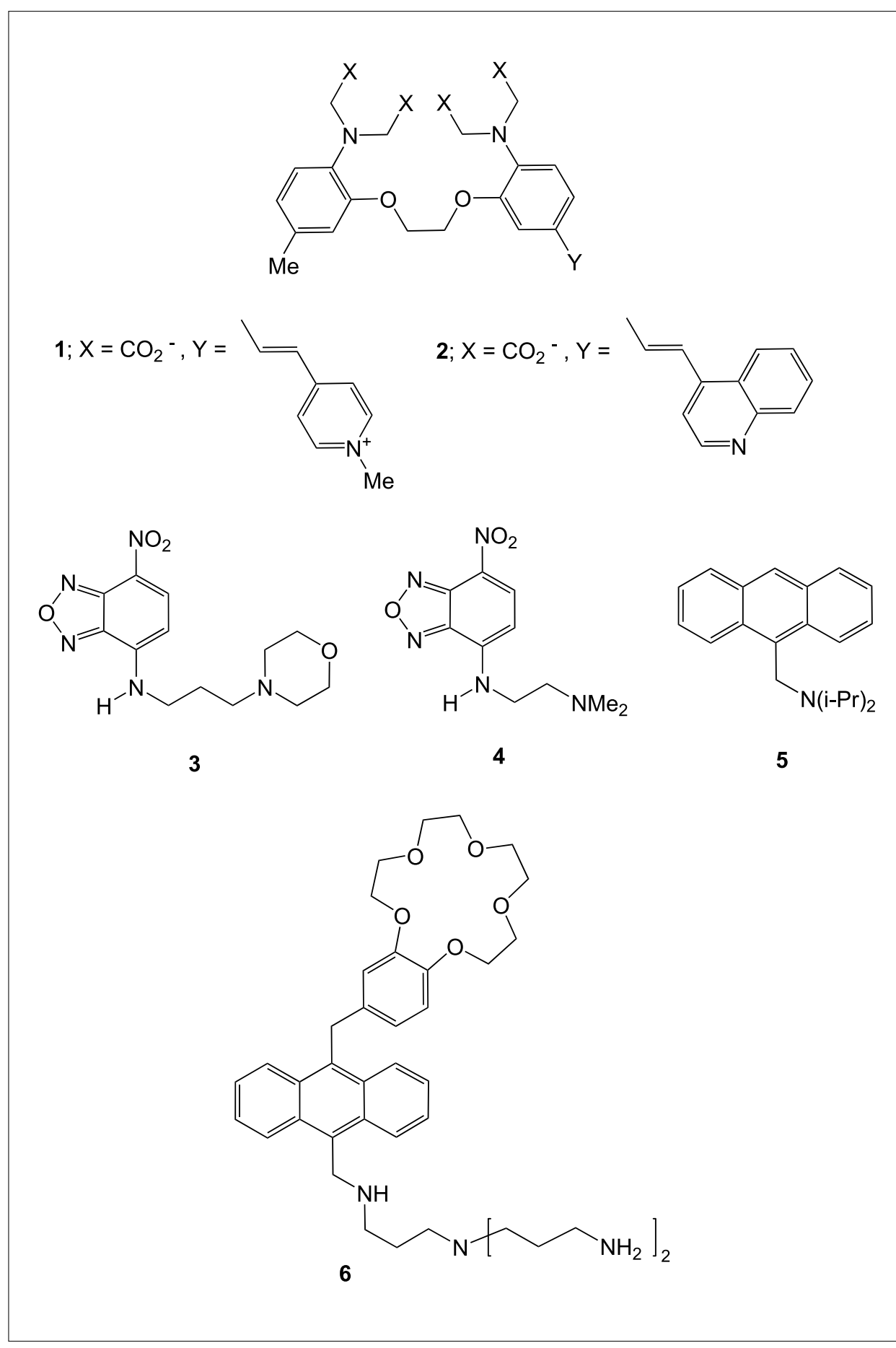

Table 1. Truth tables demonstrating superposition of logic configurations for $\mathbf{1}$

\begin{tabular}{lllll} 
Input & \multicolumn{4}{c}{ Output (transmittance) } \\
& $462 \mathrm{~nm}$ & $363 \mathrm{~nm}$ & $401 \mathrm{~nm}$ & $595 \mathrm{~nm}$ \\
$\mathrm{Ca}^{2+}$ & YES & NOT & PASS 0 & PASS 1 \\
0(low, $\left.<10^{-9} \mathrm{M}\right)$ & 0(low, 1) & 1(high, 35) & 0(low, 5) & 1(high, 100) \\
1(high, 10-2.3 M) & 1(high, 68) & O(low, 1) & 0(low, 5) & 1(high, 100)
\end{tabular}

as the input and the transmittance at a chosen wavelength as the output. YES logic occurs when a 'high' input gives rise to a 'high' output and a 'low' input produces a 'low' output. We can adopt a binary code by assigning any 'high' signal as 1 and any 'low' signal as 0 . Of course, computer scientists and engineers do this all the time but now we chemists can do it too concerning photochemical phenomena. Table
1 shows how all four of the single-input binary logic operations can be achieved by choosing the correct wavelengths from Fig. 1. However, we note something in the performance of these little molecules that silicon computer technologists can presently only dream about. All four possible logic operations occur simultaneously within the same set of molecules if we care to monitor the transmittances at the appropriate wavelengths. This is related to the effect of superposition which is discussed by physical and mathematical scientists concerning quantum computation [5]. Unlike classical bits of information, quantum bit strings can exist simultaneously in all possible states. It is to be noted however, that superposition in the molecular cases applies to the logic gates rather than to the bits that they operate on. The molecular performance becomes possible because it is easy to simultaneously observe multiple wavelengths from a sample. To locate integrated 'chromophore-receptor' systems we need look no further than chemical indicators [6]. The startling conclusion is that quantum computing systems have been lurking in school laboratories during all these years unknown to generations of schoolchildren and their teachers.

\section{3. 'Receptor ${ }_{1}$-Chromophore- Receptor ${ }_{2}$ ' Systems}

A 'Receptor ${ }_{1}$-Chromophore-Receptor $_{2}$ ' system [3] transforms into a 'Receptor $_{1}{ }^{\mathrm{d}+}$ Chromophore ${ }^{* \mathrm{~d}-}$-Receptor ${ }_{2}$ ' system upon photoexcitation. Selectively binding, say, $\mathrm{Ca}^{2+}$ at 'Receptor ${ }_{1}$ ' would then naturally destabilize the excited state by electrostatic repulsion, causing a blue shift in the UV-Vis absorption spectrum. Binding another species such as $\mathrm{H}^{+}$with similar selectivity at 'Receptor ${ }_{2}$ ' would stabilize the excited state by electrostatic attraction, causing a red shift. Simultaneous offering of both $\mathrm{Ca}^{2+}$ and $\mathrm{H}^{+}$to the system would cause almost no change, i.e. the same situation as when both inputs were absent. 2 [3] illustrates this idea very well (Fig. 2). This can be viewed as the XOR logic operation when the transmittance is measured at $387 \mathrm{~nm}$ (Table 2). While this and closely related logic operations have been demonstrated before [7], the present approach is very general and avoids acid-base neutralization which can be tricky to apply when running one gate in the presence of another. This situation arose in our unprecedented demonstration of numeracy in small molecules [8]. This example of number addition was a clear signal that little molecules could perform everyday computations as carried out by primary schoolchildren everywhere. Molecular computation goes from strength to strength [9]. 


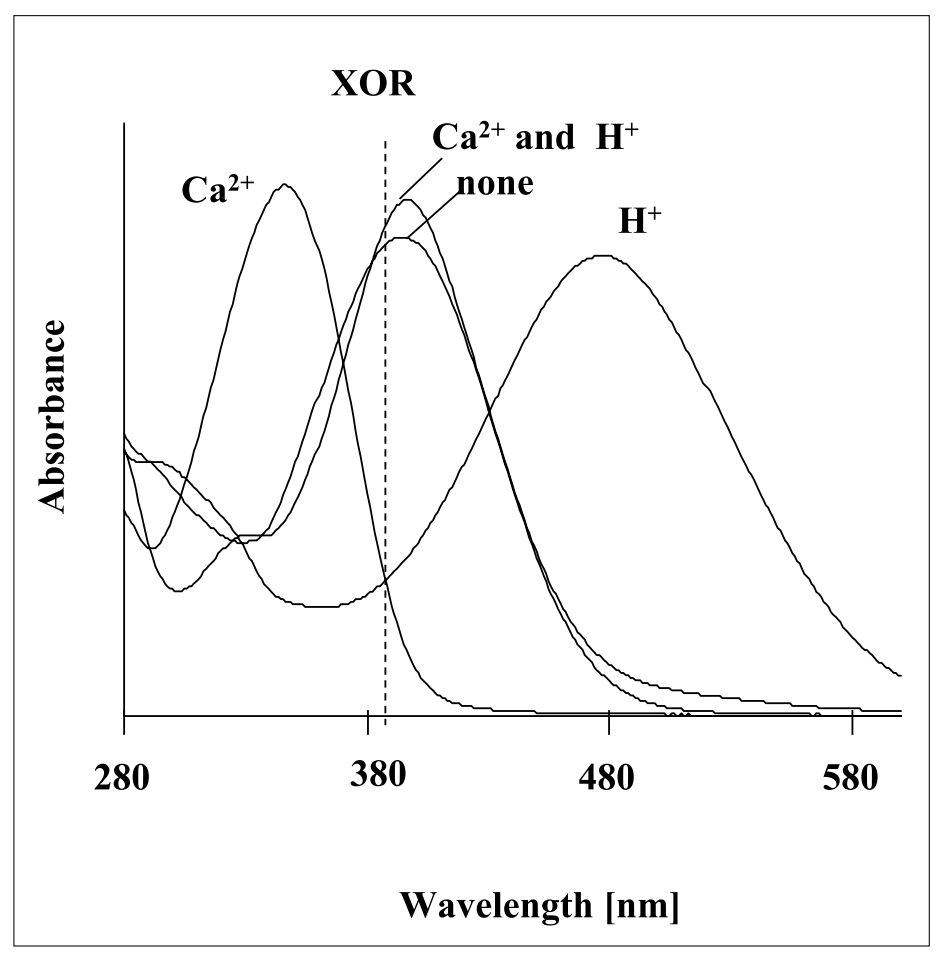

Fig. 2. XOR logic with 2, transmittance observed at $387 \mathrm{~nm}$

Table 2. Truth table showing XOR logic with 2

\begin{tabular}{|c|c|c|}
\hline Input $_{1}$ & Input $_{2}$ & $\begin{array}{l}\text { Output (transmittance) } \\
387 \mathrm{~nm}\end{array}$ \\
\hline $\mathrm{Ca}^{2+}$ & $\mathrm{H}^{+}$ & XOR \\
\hline $\mathrm{O}\left(\right.$ low, $\left.<10^{-9} \mathrm{M}\right)$ & $0\left(\right.$ low, $\left.10^{-9.7} \mathrm{M}\right)$ & O(low, 16) \\
\hline $\mathrm{O}\left(\right.$ low, $\left.<10^{-9} \mathrm{M}\right)$ & 1 (high, $10^{-5.6} \mathrm{M}$ ) & 1 (high, 59) \\
\hline 1 (high, $10^{-2.3} \mathrm{M}$ ) & $0\left(\right.$ low, $\left.10^{-9.7} \mathrm{M}\right)$ & 1 (high, 58) \\
\hline 1 (high, $10^{-2.3} \mathrm{M}$ ) & 1 (high, $\left.10^{-5.6} \mathrm{M}\right)$ & O(low, 15) \\
\hline
\end{tabular}

bance of the absorption spectrum at all [1]. The fluorescence emission spectra of $\mathbf{3}$ are strongly dependent on $\mathrm{pH}$ in both the alkaline range and in the acidic/neutral $\mathrm{pH}$ range with a clear plateau in-between. There is a strong switching 'on' of fluorescence with an FE (fluorescence enhancement) of 30 with a corresponding $\mathrm{pK}_{\mathrm{a}}$ value of 9.3 . The acidic/neutral region also shows a further large increase but the FE value is only 2.7 simply because it is calculated from a far higher baseline of the plateau reached following the protonation within the alkaline region. The corresponding $\mathrm{pK}_{\mathrm{a}}$ value is 6.7 . 3 is a fortunate case where the ICT and the PET behaviours are clearly separated in $\mathrm{pH}$ space because the $\mathrm{pK}_{\mathrm{a}}$ value of the morpholine group is rather low due to the electron withdrawing oxygen. Furthermore, the fluorescence quenching by PET is kept at a manageably low rate by using the rather long trimethylene spacer. Sufficient fluorescence quantum yield is then left over for quenching when the 4-NH is deprotonated in the alkaline range. Such systems show tristability: three $\mathrm{pH}$-independent signal regions at acidic, alkaline and intermediate pH ranges (Fig. 3) [12].

A relative 4 allows us to test the ability of rather basic sensors to respond to transition metal ions in aprotic media - a subfield which has received quite a lot of attention in recent years [13][14]. Indeed, 4 produces large $\mathrm{FE}$ values in response to chromium (III) chloride hexahydrate in acetonitrile [13]. However, a classical PET sensor $\mathbf{5}$ for $\mathrm{H}^{+}$was especially sterically crowded to produce a FE value almost as large. Metal ion coordination is expected to be more sensitive to steric bulk in the ligand than protonation. $\mathbf{5}$ is expected to be much

\section{4. 'Fluorophore-Receptor ${ }_{1}$-Spacer- Receptor ${ }_{2}$ 'Systems}

3 [10] has an amine as a receptor for $\mathrm{H}^{+}$and a popular biochemical fluorophore. But the latter also carries a deprotonatable $\mathrm{N}-\mathrm{H}$ group, which swings into action at sufficiently alkaline $\mathrm{pH}$ values. Therefore 3 fits the 'Fluorophore-Receptor ${ }_{1}$-SpacerReceptor $_{2}$ ' system. The absorption spectra of $\mathbf{3}$ are strongly dependent on $\mathrm{pH}$ in the alkaline range with a large $\mathrm{H}^{+}$-induced red shift $(77 \mathrm{~nm})$, but much less so in the acidic/ neutral $\mathrm{pH}$ range showing only a small $\mathrm{H}^{+}$induced blue shift $(8 \mathrm{~nm})$. The former behaviour illustrates ICT sensory behaviour as in common $\mathrm{pH}$ indicators [6], whereas the mild response in the acidic/neutral range is observed for fluorescent PET pH sensors, which have significant electrostatic interactions across the spacer [11]. Of course, ideal PET sensors should show no distur-

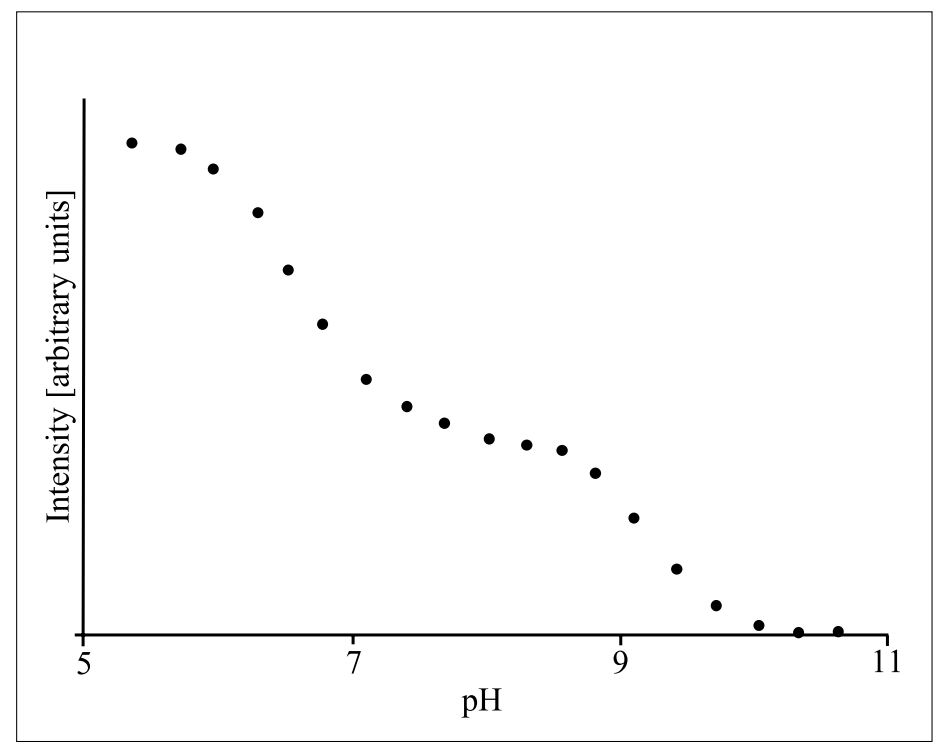

Fig. 3. Intensity (at the fluorescence band maximum) - pH profile of 3 (when excited at an isosbestic point) 
poorer than 4 for metal binding, because the former lacks chelation possibilities. Equally importantly, $\mathrm{Cr}^{3+}$ is known to be a kinetically inert ion, which will not exchange members of its first coordination sphere within the timescale of a fluorescence spectroscopic experiment [15]. So it appears that the large FE values are a result of acid-base reactions rather than metal coordination to sensors such as 4 . Where do the acid-base reactions come from? Water ligands in the coordination sphere of transition metal ions of high charge are known to be quite acidic [15]. So these can interact with the basic receptor units of the sensors. This means that strong basicity can be a pitfall which needs to be avoided when designing PET sensors for transition metal ions. Classical analytical chemistry accounts for protonation of ligands in water by employing conditional formation constants [16], for instance. So sensor designers would be wise to follow the analytical chemists into water or at least mixed aqueous solvents as the medium with $\mathrm{pH}$-buffering.

\section{5. 'Receptor -Spacer $_{1}$-Fluorophore- Spacer $_{2}-$ Receptor $_{2}$ 'Systems}

6 [17] is a 'Receptor ${ }_{1}$-Spacer $_{1}$-Fluorophore-Spacer -Receptor $_{2}$ ' system combining a textbook hydrocarbon fluorophore with a benzo-15-crown-ether unit as 'Receptor' ${ }_{1}$ and a partially protonatable tetraamine as 'Receptor ${ }_{2}$. Then, $\mathrm{Na}^{+}$and anionic phosphate species serve as inputs into the two receptors respectively. Each of these species block pre-existing PET channels according to literature precedents in simpler 'Fluorophore-Spacer-Receptor' systems [18][19]. So strong fluorescence is visible only when the ion-pair of sodium phosphate is presented to $\mathbf{6}$ in methanol/ water $1: 1(\mathrm{v} / \mathrm{v})$ at $\mathrm{pH} 8$. This is an example of AND logic behaviour. AND logic was the first indication that molecules could perform some of the operations [20] that modern computer technology was built on [21]. Direct detection of ion-pairs brings AND logic into useful analytical sensing situations. The experimental observation in the present case is clouded by the fact that 'innocent' ions like $\mathrm{Cl}^{-}$show significant interactions with the protonated tetraamine unit of $\mathbf{6}$ in the mixed aqueous solution employed in the experiment. Nevertheless, next-generation systems can improve on this aspect so that sensing of coincident species becomes practical.

\section{Acknowledgements}

We close this thumbnail sketch of business at Belfast by thanking the European Social Fund, the Department of Employment and Learning in Northern Ireland, Invest NI (RTD COE 40) and the Japan Society for the Promotion of Science for their support.

\section{Received: March 1, 2005}

[1] R.A. Bissell, A.P. de Silva, H.Q.N. Gunaratne, P.L.M. Lynch, G.E.M. Maguire, K.R.A.S. Sandanayake, Chem. Soc. Rev. 1992, 21, 187-195.

[2] A.P. de Silva, H.Q.N. Gunaratne, T. Gunnlaugsson, A.J.M. Huxley, C.P. McCoy, J.T. Rademacher, T.E. Rice, Chem. Rev. 1997, 97, 1515-1566.

[3] A.P. de Silva, N.D. McClenaghan, Chem. Eur. J. 2002, 8, 4935-4945.

[4] A.P. de Silva, N.D. McClenaghan, C.P. McCoy, in 'Electron Transfer in Chemistry', Ed. V. Balzani; Wiley-VCH, Weinheim, 2001, Vol. 5 p. 156; A.P. de Silva, N.D McClenaghan, C.P. McCoy, in 'Molecular Switches', Ed. B.L. Feringa, WileyVCH, Weinheim, 2001, p. 339; F.M. Raymo, Adv. Mater. 2002, 14, 401-407; G.J. Brown, A.P. de Silva, S. Pagliari, Chem. Commun. 2002, 2461-2463; V. Balzani, M. Venturi, A. Credi, 'Molecular Devices and Machines', Wiley-VCH, Weinheim, 2003; A.P. de Silva, N.D. McClenaghan, Chem. Eur. J. 2004, 10, 574-586.

[5] M.A. Nielsen, I.L. Chuang, 'Quantum Computation and Quantum Information', Cambridge University Press, Cambridge, 2000.

[6] 'Indicators', Ed. E. Bishop, Pergamon Press, London, 1972.

[7] A. Credi, V. Balzani, S.J. Langford, J.F. Stoddart, J. Am. Chem. Soc. 1997, 119, 2679-2680; M. Asakawa, P.R. Ashton, V. Balzani, A. Credi, G. Mattersteig, O.A. Matthews, M. Montalti, N. Spencer, J.F. Stoddart, M. Venturi, Chem. Eur. J. 1997, 3, 1992-1996; F. Pina, M.J. Melo, M. Maestri, P. Passaniti, V. Balzani, J. Am. Chem. Soc. 2000, 122, 4496-4498.

[8] A.P. de Silva, N.D. McClenaghan, J. Am. Chem. Soc. 2000, 122, 3965-3966.

[9] M.N. Stojanovic, D. Stefanovic, Nature Biotechnol. 2003, 21, 1069-1074; A. Okamoto, K. Tanaka, I. Saito, J. Am. Chem. Soc. 2004, 126, 9458-9463; D. Margulies, G. Melman, C.E. Felder, R. Arad-Yellin, A. Shanzer, J. Am. Chem. Soc. 2004, 126, 15400-15401.

[10] J.F. Callan, A.P. de Silva, A.J.M. Huxley, J. Ferguson, A.M. O'Brien, Tetrahedron 2004, 60, 11125-11131.

[11] A.P. de Silva, H.Q.N. Gunaratne, Lynch P.L.M., A.L. Patty, G.L. Spence, J. Chem. Soc., Perkin Trans. 2 1993, 1611-1616.

[12] R. Grigg, W.D.J.A. Norbert, Chem. Commun. 1992, 1298-1299; C. Di Pietro, G. Guglielmo, S. Campagna, M. Diotti, A. Manfredi, S. Quici, New J. Chem. 1998, 22, 1037-1039; L. Fabbrizzi, M. Licchelli, P. Pallavicini, Angew. Chem., Int. Engl. 1998, 37, 800-802; F. Pina, M.J. Melo, M.A. Bernardo, S.V. Luis, E. Garcia-Espana, J. Photochem. Photobiol. A Chem.
1999, 126, 65-69; G. Dilek, E.U. Akkaya, Tetrahedron Lett. 2000, 41, 3721-3724.

[13] B. Ramachandram, A. Samanta, Chem. Commun. 1997, 1037-1038; B. Ramachandram, A. Samanta, Chem. Phys. Lett. 1998, 290, 9-16; B. Ramachandram, A. Samanta, J. Phys. Chem. A. 1998, 102, 10579-10587.

[14] K.A. Mitchell, R.G. Brown, D. Yuan, S-C. Chang, R.E. Utecht, D.E. Lewis, J. Photochem. Photobiol. A: Chem. 1998, 115 , 157-161; N.B. Sankaran, S. Banthia, A. Samanta, Proc. Ind. Acad. Sci. Chem. Sci. 2002, 539-545; I. Grabchev, X. Qian, Y. Xiao, R. Zhang, New J. Chem. 2002, 26, 920-925; R. Badugu, Chem. Lett. 2002, 52-53; S. Banthia, A. Samanta, J. Phys. Chem. B. 2002, 106, 5572-5577; I. Grabchev, J.-M. Chovelon, X. Qian, J. Photochem. Photobiol. A: Chem. 2003, 158 , 37-43; I. Grabchev, J.-M. Chovelon, X. Qian, New J. Chem. 2003, 27, 337-340; Y. Xiao, X. Qian, Tetrahedron. Lett. 2003, 44, 2087-2090.

[15] F.A. Cotton, G. Wilkinson, 'Advanced Inorganic Chemistry', Wiley-Interscience, New York, 1966.

[16] A. Ringbom, 'Complexation in Analytical Chemistry', Interscience, New York, 1963.

[17] A.P. de Silva, G.D. McClean, S. Pagliari, Chem. Commun. 2003, 2010-2011.

[18] A.P. de Silva, K.R.A.S. Sandanayake, Chem. Commun. 1989, 1183-1184.

[19] M.E. Huston, E.U. Akkaya, A.W. Czarnik, J. Am. Chem. Soc. 1989, 111, 8735-8736.

[20] A.P. de Silva, H.Q.N. Gunaratne, C.P. McCoy, Nature 1993, 364, 42-44.

[21] A.P. Malvino, J.A. Brown, 'Digital Computer Electronics', 3rd Ed., Glencoe, Lake Forest, 1993. 